\title{
COMPLEXITY ANALYSIS OF THE FUTURE CAR FOR AUTOMOTIVE LOGISTICS
}

\author{
Konrad Pawlikowski ${ }^{(a)}$, Michael Toth ${ }^{(b)}$

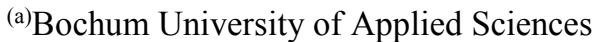

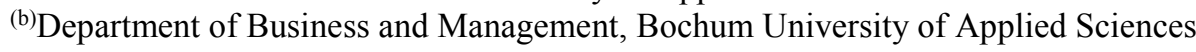 \\ (a)konrad.pawlikowski@hs-bochum.de, ${ }^{(b)}$ michael.toth@hs-bochum.de
}

\begin{abstract}
The automotive industry has to manage radical changes. Especially, the complexity of parts and variants changed by the technological trends e-mobility and the increasing introduction of intelligent assistance systems that are based on embedded systems. Moreover, not only the car complexity is affected. To realise the impact of change, a holistic complexity analysis of the product car has to be done. Such analysis is particularly relevant for logistics, which acts as a cross-divisional function between technology development, procurement, production, sales and after-sales. Therefore, this contribution presents identified impact areas in the field of the automotive logistics followed by developed indicators to realise an approach for a holistic complexity analysis. This is necessary to identify impacts on logistics processes, e.g. sourcing strategies.
\end{abstract}

Keywords: automotive logistics, car complexity, e-mobility, embedded systems

\section{INTRODUCTION}

Since Henry Ford introduced mass production in the early 20th century, the automotive industry is facing the biggest challenge in its history. (Holweg and Pil 2004). The megatrends autonomous driving and the field of emobility are becoming increasingly important and will significantly change the car and its production and logistics structures.

Original equipment manufacturers (OEMs) nowadays offer their customers a huge variety of models to compete in international markets. Moreover, those models can be individualised by several hundred options (Dörmer 2013). Among these options are design elements (e.g. car paint), functional components (e.g. gear system) and recently more and more assistance systems (e.g. Adaptive Cruise Control (ACC) as a driver assistance system). Furthermore, the OEMs product range is constantly updated with increasing frequency (Schuberthan and Potrafke 2007).

The management of product variety and the resulting complexity is decisive for the success of the OEMs. Offered variety supports the maintenance of market share, revenue and thus profit. Nevertheless, variety also leads to complexity in the field of product portfolio, product architecture and in supply chain processes.
(Götzfried 2013) Especially the mentioned trends emobility and the increasing number of embedded systems to integrate intelligent assistance systems have led to a radical increase in complexity of parts and variants (Kampker et al. 2016, Krumm et al. 2014).

Changes within the complexity (increase as well as decrease) in the product architecture and in OEM's portfolio is a challenge itself. Only with a high degree of transparency, the OEMs are able to manage the complexity. For example on the portfolio side, the OEMs are able to identify a non-efficiently level of complexity to handle. (Götzfried 2013) This transparency applies in particular to logistics that has to guarantee material availability and quality under demand uncertainty. In addition, logistics acts as a cross-divisional function between technology developments, procurement, production, sales and after-sales. Therefore, it is essential that the so-called product representation (information basis) depicts all car characteristics (especially dependencies between parts, components and car features) and provides transparent holistic information for all logistics processes. This product representation includes a product structure, its options as well as its components and their dependencies. (Fruhner et al. 2017) Here, this contribution presents an identification of the impact areas on logistics caused by the future car in the field of the automotive industry. Based on these findings and scientific literature, indicators for a complexity analysis approach are derived. These indicators shall replicate the complexity numerically expressed and therefore be used as a basis for a decision support regarding logistics strategy for example in terms of sourcing strategies.

The paper is structured as follows: relevant terms and concepts will be defined in section 2 , attached by a discussion of challenges in the automotive industry. This leads to an identification of impact areas on logistics. Subsequently, complexity indicators are derived related to the identified impact areas in section 3. Moreover, a holistic complexity analysis approach is presented. The contribution concludes with a summary of key insights and an outlook on further research. 


\section{CHALLENGES FOR THE AUTOMOTIVE INDUSTRY AND CORRESPONDING IMPACT AREAS ON LOGISTICS}

After the automotive customer has opted for a car series and a related model, the model can be further individualised by so-called options and option packages. These - sometimes - several hundred options include in addition to exterior, interior and security equipment, nowadays also driving assistance systems (e.g. parking aid) (eVchain 2014). The high degree of individual configuration is a crucial marketing factor for premium OEMs, but it contributes as well significantly to the complexity of the product car. Moreover, automotive customers have to deal with the rapid change of variants and options (Ebel and Hofer 2014).

An effective automotive supply chain logistics management requires the synchronization of resource and component requirements with resource capacities and constraints in the production and supply chain. To achieve this, the logistics planner needs a holistic information set. However, relevant data is typically kept in a highly fragmented information landscape ((Bockholt 2012, Meyr 2004, Stäblein 2008)) and must therefore be integrated into a transparent and efficient form of product representation. This product representation must contain all information that is necessary to grasp the expected or realised needs of the customer (e.g. model volume or option quotas). (Fruhner et al. 2017)

The compatibility of car models and their options is described by a highly complex set of technical rules, while the related material items of the corresponding fully-configured car and the corresponding material items are described by the so-called bill of material (BOM) (Pawlikowski et al. 2016).

Regarding the offered car series variety, the trend of emobility leads to radical changes in the car architecture. Electric vehicles differ in various components in comparison to conventional vehicles (vehicles with combustion engines), for example all components related to the exhaust system are obsolete, but the share of electronic components is much higher. The compatibility of the electronic components and the connection of the energy consuming components to the energy source(s) in the car has to be ensured. (Fruhner et al. 2017) In addition, the number of embedded systems and software within the powertrain is generally increasing (Nikowitz 2016). All these facts lead to the impact area "product and production complexity" as an object of this research. Meanwhile, a shift in the competence of OEMs has been identified and analysed since many years. As the product car includes many simple parts, automotive suppliers produce and develop more and more complex modules (Trojan 2007). OEMs on the other hand focus more and more on the assembly of supplied parts and modules, the coordination of suppliers, the product marketing and the distribution of the product car (Meissner 2009). Today, different supply concepts (e.g. just-in-time delivery), global locations of supplier, long distances, and varying material flow systems increase the complexity (Fruhner et al. 2018).
The OEM's product range will be jointly determined by conventional and electric vehicles in the foreseeable future (Göpfert et al. 2017). Therefore, the effort for supplier selection, triggering and monitoring order processes will increase. Hence, the second impact area on automotive logistics is the field of "supply chain complexity".

The classical product life cycles are seven years in the automotive industry. Rather, the development lead-time is three years, thus the technologies used during this period are ten years old at the end of their life cycle. In comparison to current technology development, such a cycle is far too long and leads to obsolete technologies very quickly. (Kampker et al. 2017) Many electronic components in a car like navigation systems are outdated after a few years of use. Such cars can only be sold to second-hand customers with a great loss of value. This can be countered by updating the components, e.g. by integrating Apple CarPlay into an end-of-life vehicle. (Moynihan 2014). Besides, the share of the electric and electronic components increases within the car (eVchain 2014).

Thus, a continuous update of the vehicles, similar to software, must be enabled to improve sustainability. These effects extend to the after-sales and also spare-part business. Concluding, the "innovation cycles complexity" is a third impact area on automotive logistics.

As summary, the identified impact areas regarding the challenges within the automotive industry are:

- product and production complexity,

- supply chain complexity and

- innovation cycles complexity.

To be able to support decision-making within logistics processes, indicators will be derived in the next section. The aim is to use them as a holistic complexity approach based on the comparison of the "future" and "conventional" car to understand if the automotive logistics is also facing big changes. Moreover, it shall be used to evaluate the complexity of the car in the future and support decisions for example in the field of sourcing strategies.

\section{HOLISTIC ANALYSIS APPROACH AND ITS COMPLEXITY INDICATORS}

The scientific application of the term "complexity" is interdisciplinary and finds expression in a multitude of sciences (cf. (Kirchhof 2003)). Maguire et al. (2011) emphasized complexity as a significant growing research topic in the field of natural and social sciences. Moreover, the management of complexity represents a crucial managerial challenge in organisation (Morieux 2011, Sargut and McGrath 2011).

An overview of complexity theories and their interpretations is given by Meyer as well as Kirchhoff (Kirchhof 2003, Meyer 2007). For example in the field of systems theory, complexity is defined by the number of elements, their relations, and the change of elements and relations over time (Meyer 2007). Related to the system structure, static or structural complexity arises, 
whereby dynamic or operative complexity describes the system behavior over time (Schuh 2005).

Another view regarding the management of complexity is the differentiation between external and internal complexity (Kaiser 1995, Schuh and Schwenk 2001). Here, companies try to bridge the gap between customers' demand requirements and the product variety. This results in a certain level of product and process complexity (Marti 2007, Schuh and Schwenk 2001).

As this contribution presents a holistic approach to analyse the complexity of the product car, the opportunities of evaluation are point of interest. Here, two types of complexity evaluation exist: monetary and non-monetary approaches. Both approaches allow manufacturing companies to set and track quantifiable targets. Cost calculations represent monetary approaches, whereby non-monetary approaches are indicators and indices that are not directly transferred to costs. (Götzfried 2013)

Based on this differentiation, a non-monetary evaluation related to the identified impact areas is used as an approach to analyze the car complexity in the field of automotive logistics. It shall consider the changes within the car architecture and the corresponding logistics processes. Hereby, a differentiation between external and internal factors will be considered.

\subsection{Product and Production Complexity}

The more complex a product to be manufactured is, the more complex are the processes required for production as well as those existing within the remaining value chain (Schaffer 2010).

As the product architecture belongs to the field of product complexity, the following section considers the differentiation between external and internal variety. External variety is the product variety offered to the customer. In the automotive industry, Lechner et al. (2011) refers to $10^{20}$ different configurations as product variety for several models of German premium OEMs. The total number of variants is responsible for ensuring that within a value-added process, e.g. in mechanical production, assembly or planning, non-value-adding activities are carried out and so-called reactive power is generated (Schaffer 2010).

Therefore, the external variety as a crucial indicator is point of interest. According to Rosenberg (2002) the theoretical variety $v^{t h}$, i.e. the external variety, can be calculated by the multiplication of number of mandatory variety and optional variety (1). Here, $x_{m}$ is defined as the number of expressions of the mandatory characteristic $m$ and $y_{k}$ as the number of values of the optional characteristic $k$. The related amount of the characteristics are $M$ and $K$.

$v^{t h}=\prod_{m=1}^{M} x_{m} * \prod_{k=1}^{K}\left(y_{k}+1\right)$

It shall be highlighted, that $v^{\text {th }}$ is a theoretical number. Technical restrictions prohibit options for specific models (e.g. no 17' tires for convertibles), force specific combinations of options (e.g. LED head light only in combination with LED back lights) or prohibit combinations (e.g. a navigation system rules out all other radios). Schaffer, for example, divides the variety into the practically producible number of variants, the effectively produced number of variants, the technically permissible number of variants and the theoretical number of variants (Schaffer 2010). Scavarda et al. (2010) formulate the producible variety as a subtraction of theoretical variety and restrictions, that affect models and/or bodystyles.

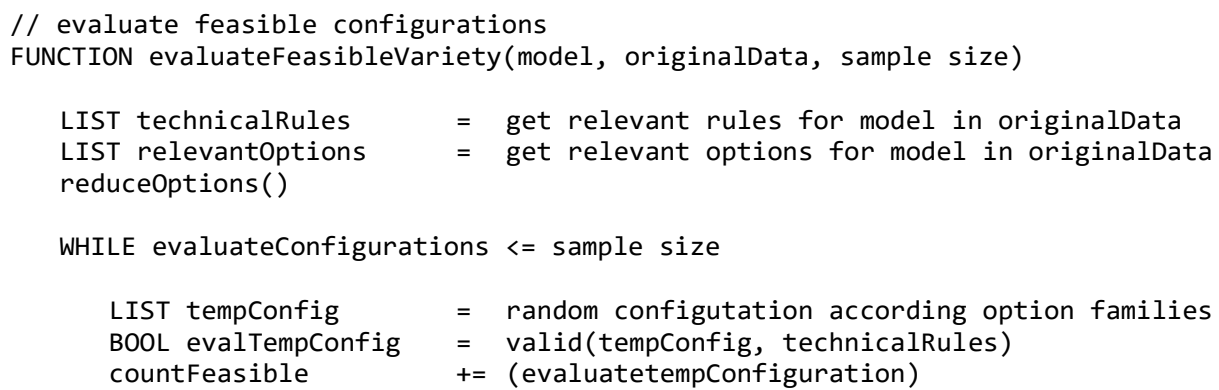

Pseudocode 1: Evaluate feasible variety

The exact estimation of the feasible variety $v^{f}$ is not possible in an appropriate time, for example related to the mentioned theoretical variety of $10^{20}$ and 60 relevant technical rules, it would result in $60^{21}$ evaluations. Therefore, the authors approximate the number of feasible configurations $v^{f}$ (pseudocode 1). Based on the analysed car model random configurations are determined and these configurations are tested if the relevant technical rules are valid. To reduce the amount 
of calculation, options that will be set independent of the configuration are put in a "basis configuration".

Based on external variety and demands, companies translate into value chain requirements and create internal variety (Pil and Holweg 2004). As the variety of models grows, so does the number of components in the company. This fact leads to an increase in the number of goods to be procured (Kestel 1995).

According to MacDuffie et al. (1996) internal variety can be differentiated in a fundamental, peripheral and intermediate level. The level of fundamental variety is represented by variation of base products, platforms and models. The amount and variation of offered options belongs to the peripheral variety. Intermediate level is characterized by part variety, reflecting product design and the supply chain (e.g. number of suppliers). Accordingly, related to a specific model, $p^{\text {mo }}$ represents the intermediate variety with respect to unique parts $p^{u}$ (3).

$p^{m o}=n\left(p^{u}(\right.$ model $\left.)\right)$

Furthermore, in the context of external variety, the amount of offered options can be indexed as the degree of individualisation. The potential individualisation used by OEMs as a marketing factor affect the "Order Penetration Point" that represents the transition from forecast-driven and customer-neutral to customer orderdriven production planning (Klug 2010). Thus, the degree of individualisation $d^{i}$ is calculated by division of the number of choosable (optional) options $o p^{o}$ and the corresponding total number of options (4).

$d^{i}=\frac{n\left(o p^{o}\right)}{n(o p)}$

Here, $d^{i}$ is analogous to $v^{\text {th }}$ a theoretical indicator. This is caused by the technical rules that prohibit all optional options to be set at the same time. An approximation of a real number of independent optional options $a o^{i}$ can be estimated by (5).

$a o^{i}=n\left(o p^{o}\right)-\log _{2} \frac{v^{t h}}{v^{f}}$

Based on Lechner (2011) the so-called variant density and variant heterogeneity can be used as indications of product complexity. While the density of variants can be determined with regard to the product range, the characteristic number of variant heterogeneity is related to option families (Lechner 2011). The variant density $d^{v}$ can be estimated by counting the base parts $p_{i}^{b}$ and dividing by the amount of parts for a specific model (6).

$d^{v}=\sum_{i=1}^{n} p_{i}^{b} / \sum_{i=1}^{n} p_{i}$

The variant heterogeneity $h^{v}$ of an option family is an indicator that shows how strongly variant number changes can affect the logistics system. The result of the value is 1 if a variant family is absolutely heterogeneous and 0 if there are no similarities between the variant characteristics. Therefore, it enables the evaluation regarding scale effects. It is calculated from the sum of attributes $a_{i}$, which have the same value $a g_{j}$ for all variants, in relation to the sum of all characteristics (7).

$h^{v}=\sum_{j=1}^{m} a g_{j} / \sum_{i=1}^{n} a_{i}$

Regarding to the product architecture not only the physical part of car characteristics has changed. The digitisation of the car has introduced new and changed dependencies among components, e.g. the compatibility of hardware and software. Among other impacts, the compatibility has to be ensured with respect to spare parts and maintenance. Such dependencies are described by the mentioned technical rules. Therefore the next point of interest is the complexity of those. Based on Lechner (2011), the indicator "connectivity of variants" ${ }^{c}{ }^{c h}$ analyses the amount of relations between the option characteristics (8). The amount of characteristic dependencies to other characteristics $m^{\text {ch,re }}$ is put in relation to the number of characteristics.

$c^{c h}=m^{c h, r e} / m^{c h} \forall c h$

The higher the connectivity, the greater the impact of variant changes. The changes in the number of variants of an existing variant family, e.g. an additional motor, lead to additional variants of other variant families (e.g. transmission).

A similar indicator to evaluate the complexity of the dependencies regarding the characteristics is the analysis of the corresponding technical rules (noted as boolean rules) (9). One indicator is the length of boolean rules $l(r)$. In general, the complexity of boolean rules can be evaluated regarding their depth $d(r)$. It is defined as the maximum number of steps to evaluate from input to output (Paterson 1992). A third part is represented by the average priority of boolean operators $a p(r)$.

$c^{r}=l(r) * d(r) * a p(r) \forall r$

Based on this determination, the average of $c^{r}$ is supposed to imply the complexity of the model under consideration. The effort of logistic processes can be supported, e.g. in the determination of forecasts and demand.

\subsection{Innovation Cycle Complexity}

As the innovation cycles accelerate, there are some factors that are relevant for the complexity analysis. To be able to manage the short innovation cycles and amount of parts, modularity and platform strategies are used in the automotive industry in the context of variant management. Related to this, the share of part modularity represents an important indicator regarding the question whether the degree of modularity is increasing in the flied of e-mobility. Gross et al. (2007) - for example describe a degree of modularity, i.e. the number of elements of a modular structure weighted with the 
production quantities. Based on this idea and under consideration of the changes from the conventional car to the "future" car, the authors decide to measure the product modularity as a share of parts related to the number of suppliers (10).

$s_{m}^{p m}=\frac{n(p)}{n(s)}$

A similar approach to handle such situation is the use of equal parts as far as possible; thus the share of equal parts $s_{m}^{e q}(11)$ is an indicator for complexity and may support the selection of suppliers and its sourcing strategy (e. g. multiple sourcing).

$S_{m}^{e q}=\frac{n\left(p^{e q}\right)}{n(p)}$

Moreover, related to electronic parts $p^{e}$, the amount of software $p^{s w}$ within the car is significantly increasing (Hammerschmidt 2019). Here, new types of suppliers like Apple or Google are entering the automotive industry. New participants will increase the competition between the OEMs (Bob Heaney 2015). Therefore, the share of electronic parts (12) as well as the share of software elements (13) are points of interest (regarding part complexity and compatibility). The conclusion of more software components is the fact that more software updates have to be managed and the compatibility between those components have to be ensured.

$S_{m}^{e}=\frac{n\left(p^{e}\right)}{n(p)}$

$s_{m}^{s w}=\frac{n\left(p^{s w}\right)}{n(p)}$

Not only the innovation cycles accelerate, the product life cycle of the car is getting shorter. Therefore, logistics processes have to handle this, for example the forecast is getting more complex. The indicator "product lifecycle complexity" plcc ${ }^{m o}$ related to the model, is determined by the division 1 by the product life cycle PLC (14).

$\operatorname{plcc}^{m o}=\frac{1}{P L C^{m o}}$

\subsection{Supply Chain Complexity}

In general, the third part "supply chain complexity" is crucial influenced by the trend of globalisation. Global suppliers and their competition enable supply chain processes many possibilities. On the one side, the competition between the suppliers is rising, but on the other side, longer delivery times and higher logistics costs are factors for an OEM to be considered. The share of local and the number of global suppliers (15)-(16) shall implicate the complexity, for example regarding the choice of sourcing strategies.

$s_{m}^{\text {local }}=\frac{n\left(s^{\text {local }}\right)}{n(s)}$ $s_{m}^{\text {global }}=n\left(s^{\text {global }}\right)$

The increasing electrification of vehicles will shift the value added in the supply chain. Regarding the supply chain of the conventional car, $30 \%$ of the value added is generated via the power train, whereby for an electric car it amounts to $60 \%$ (caused by the battery). (Bierau et al. 2016, Pieper and Ernst o.J.) In addition, the value added of the battery cell, i.e. raw material supply and production (main part of the costs of batteries) is located outside of Europe (Pawlikowski et al. 2018).

In this context, as a non-monetary approach, the share of produced parts shall be an indicator related to the field of make-or-buy decision (17). Make-or-buy is used to decide on the own depth of value added. Even this basic decision leads to consequences with regard to logistics complexity (such as number of suppliers, variety of incoming goods) and to correspondingly necessary procurement logistics structures (Muchna et al. 2018).

$s_{m}^{p r}=\frac{n\left(p^{p r}\right)}{n(p)}$

A low vertical range of manufacture tends to lead to the delivery of more complex parts to assemblies. Just-intime (JIT)/ just-in-sequence (JIS) logistics processes with lower warehousing are more likely to be used here. These are production synchronous strategies, where components for production are delivered on exact dates in coordination with the production or assembly process. (Muchna et al. 2018)

This avoids intermediate stocks and buffers (Kestel 1995). In order to be able to meet the short delivery time, suppliers often locate themselves in close proximity to the automotive plant (Grunewald 2015). Especially if such efficient processes are or can be used, the respective share is derived (18)-(19). Based on this information and in relation to their corresponding number of suppliers, decisions and possible steps shall be assisted.

$S_{m}^{\text {local }}=\frac{n\left(p^{\text {local }}\right)}{n(p)}$

$s_{m}^{\text {global }}=\frac{n\left(p^{\text {global }}\right)}{n(p)}$

\subsection{Holistic Complexity Approach}

According to the understanding of complexity in this contribution, complexity is formed by the interplay of many dimensions. For the complete evaluation of complexity it is therefore obvious to consider complexity as a multidimensional quantity, since an adequate quantification of complexity cannot be realised by a single indicator (Scholz-Reiter et al. 2006).

Furthermore, in times of growing modularity, in which the influence of product complexity on the process can be affected by decoupling processes, late configuration, standardization, platform strategies and common parts concepts, it is important to have access to efficient tools and methods with which the influence of product structure and architecture on manufacturing processes 
and thus on costs can be investigated (Schaffer 2010). This shall support decision-making, which is a central activity in big and complex organisations, thus one of the key tasks and responsibilities of managers. (Götzfried 2013, Nutt and Wilson 2010) Moreover, to manage complexity, the transparency of variety-induced complexity represents a crucial element in order to understand its impact. (Child et al. 1991, Lechner et al. 2011). The effects of product complexity also unfold in a change in procurement complexity. For example, an expansion of the product range also has an effect on the supplier network and leads to additional costs for goods processing in the plant. Product complexity continues to have an internal influence on structural complexity, because structural adjustments must always be made as a result of changes in the product program. (Feldhuetter 2018)

In general, the aim should not be to design a minimal but rather a company complexity adapted to the situation, based on a differentiated selection of measures (Schuh 2005). Regarding the time horizon, three generic strategies for implementing efficient variant management can be distinguished: the strategy of complexity reduction, complexity control and complexity avoidance (Feldhuetter 2018).

Only with such presented holistic complexity analysis, it can be assessed to what extent logistic processes have to adapt and what the future vehicle means for variant management etc. This approach shall support processes and stakeholders in every phase of the product life cycle. Moreover, the integration of new modules, components or software components into an existing vehicle structure as well product representation and into logistics processes shall be assisted.

A visualization of the schema, covering the three impact areas, is shown in figure 1. It is based on a so-called spider chart. The method shall be used to compare the complexity of the conventional car and the "future" car in forthcoming work and enable the identification of impacts on logistics processes.

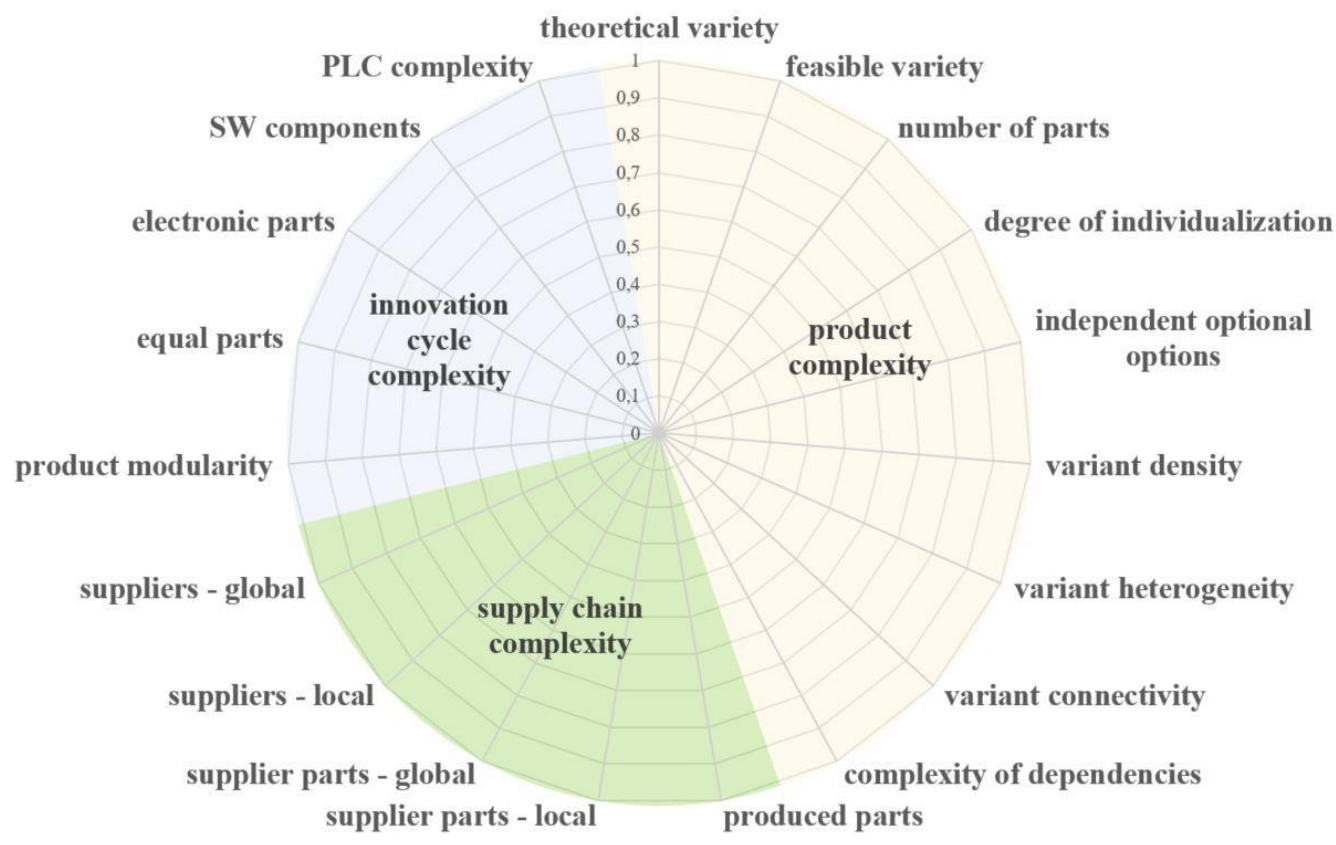

Figure 1: Spider chart for complexity analysis

\section{KEY INSIGHTS AND OUTLOOK}

The presented contribution is an important starting point, as it shows that not only the car as a product itself radically changes. Moreover, the changes affect the automotive logistics and the corresponding product representation. Hereby, in order to guarantee the availability of components and minimize obsolescence risks, it is essential that the automotive logistics has access to transparent holistic information. Especially, dependencies of technical and electronical components and the compatibility between hardware and software components have to be considered. To realise the impact of change (parts, variants, supplier locations), a holistic complexity analysis has to be done.
Based on this approach, a forthcoming work will be the evaluation of the implemented model and a comparison of the complexity of a conventional model and a "future" car to identify impacts on logistics processes. In addition, this holistic complexity analysis shall help to optimize impacts on logistics processes by simulation (for example by different scenarios within the product development).

\section{REFERENCES}

Bierau, F., Perlo, P., Müller, B., Gomez, A. A., Coosemans, T. and Meyer, G., 2016. Opportunities for European SMEs in Global Electric Vehicle Supply Chains in Europe and Beyond. In: Schulze, 
T., Müller, B. and Meyer, G., eds. Advanced Microsystems for Automotive Applications 2015Smart Systems for Green and Automated Driving: Springer, pp. 223-235.

Bob Heaney, 2015. THE EVOLUTION OF THE SUPPLY CHAIN - SPOTLIGHT ON THE AUTOMOTIVE INDUSTRY.

Bockholt, F., 2012. Operatives Störungsmanagement für globale Logistiknetzwerke: Ökonomie- und ökologieorientiertes Referenzmodell für den Einsatz in der Automobilindustrie. Thesis (PhD). TU Dortmund University.

Child, P., Diederichs, R., Sanders, F.-H., Wisniowski, S. and Cummings, P., 1991. The management of complexity. In: McKinsey Quarterly, pp. 52-68.

Dörmer, J., 2013. Produktionsprogrammplanung bei variantenreicher Fließproduktion: Untersucht am Beispiel der Automobilendmontage. Wiesbaden: Springer.

Ebel, B. and Hofer, M. B., eds., 2014. Automotive Management: Strategie und Marketing in der Automobilwirtschaft, 2nd edn. Berlin: Springer Gabler.

eVchain, 2014. Modellierung der zukünftigen elektromobilen Wertschöpfungskette und Ableitung von Handlungsempfehlungen zur Stärkung des Elektromobilitätsstandortes NRW: (EM1006 eVchain.NRW).

Feldhuetter, V., 2018. Beitrag zur modellbasierten Bewertung der Komplexität in der Montagelogistik der Automobilindustrie. Thesis (PhD). TU Dortmund University.

Fruhner, D., Klingebiel, K., Pawlikowski, K. and Toth, M., 2018. Impacts of the digitalised car on logistics. Proceedings of the 25th International Annual EurOMA Conference, June 24-26. Budapest, Hungary.

Fruhner, D., Pawlikowski, K., Klingebiel, K. and Toth, M., 2017. Efficient Product Representations for Automotive Logistics. Proceedings of the 29th European Modeling and Simulation Symposium (EMSS), pp. 100-109, September 18 - 20. Barcelona, Spain.

Göpfert, I., Braun, D. and Schulz, M., eds., 2017. Automobillogistik: Stand und Zukunftstrends[Online], 3rd edn: Springer Gabler. Available at: http://dx.doi.org/10.1007/978-3-65811103-8.

Götzfried, M., 2013. Managing Complexity Induced by Product Variety in Manufacturing Companies Complexity Evaluation and Integration in DecisionMaking. Thesis (PhD). University of St. Gallen.

Gross, W., Heimel, J., Kuhn, S. and Schwab, C., 2007. Towards case-based product and network configuration for complex construction machinery. In: Innovative processes and products for mass customization. Berlin, pp. 121-135.
Grunewald, M., 2015. Planung von Milkruns in der Beschaffungslogistik der Automobilindustrie. Wiesbaden: Springer Fachmedien Wiesbaden.

Hammerschmidt, C., 2019. E/E-Architekturen: Frischzellenkur[Online]. Available at: https:// www.car-it.com/frischzellenkur/id-0062411?cookiestate-change $=1554127222067$ (Accessed 14 April 2019).

Holweg, M. and Pil, F. K., 2004. The second century: Reconnecting customer and value chain through build-to-order: moving beyond mass and lean production in the auto industry. Cambridge, MA, USA: MIT Press.

Kaiser, A., 1995. Integriertes Variantenmanagement mit Hilfe der Prozesskostenberechnung. Thesis (PhD). University of St. Gallen.

Kampker, A., Deutskens, C., Heimes, H., Ordung, M. and Haunreiter, A., 2016. Using E-mobility as an Enabler for a Fast and Lean Product Development to Optimize the Return of Engineering with the Example of Lithium-ion Battery. Procedia CIRP vol. 50, pp. 166-172.

Kampker, A., Gerdes, J. and Schuh, G., 2017. Think Big, Start Small: Streetscooter die e-mobile Erfolgsstory: Innovationsprozesse radikal effizienter. Berlin, Heidelberg: Springer.

Kestel, R., 1995. Variantenvielfalt und Logistiksysteme: Ursachen - Auswirkungen - Lösungen[Online]. Wiesbaden, s.1.: Deutscher Universitätsverlag. Available at: http://dx.doi.org/10.1007/978-3-32299527-8.

Kirchhof, R., 2003. Ganzheitliches Komplexitätsmanagement: Grundlagen und Methodik des Umgangs mit Komplexität im Unternehmen[Online]. Wiesbaden, s.l.: Deutscher Universitätsverlag. Available at: http://dx.doi.org/ 10.1007/978-3-663-10129-1.

Klug, F., 2010. Logistikmanagement in der Automobilindustrie: Grundlagen der Logistik im Automobilbau. Berlin: Springer.

Krumm, S., Schopf, K. D. and Rennekamp, M., 2014. Komplexitätsmanagement in der Automobilindustrie - optimaler Fit von Vielfalt am Markt, Produktstruktur, Wertstrom und Ressourcen. In: Ebel, B. and Hofer, M. B., eds. Automotive ManagementStrategie und Marketing in der Automobilwirtschaft. 2nd edn. Berlin: Springer Gabler, pp. 189-205.

Lechner, A., 2011. Modellbasierter Ansatz zur Bewertung vielfaltsinduzierter Logistikkomplexität in der variantenreichen Serienfertigung der Automobilindustrie. Thesis (PhD). TU Dortmund University.

Lechner, A., Klingebiel, K. and Wagenitz, A., 2011. Evaluation of product variant-driven complexity costs and performance impacts in the automotive logistics with variety-driven activity-based costing. 
International MultiConference of Engineers and Computer Scientists, pp. 1088-1096, March 16 - 18. Hong Kong.

MacDuffie, J. P., Sethuraman, K. and Fisher, M. L., 1996. Product Variety and Manufacturing Performance: Evidence from the International Automotive Assembly Plant Study. Management Science vol. 42, pp. 350-369.

Maguire, S., Allen, P. and McKelvey, B., 2011. Complexity and Management: Introducing the SAGE Handbook. In: S. Maguire, P. Allen and B. McKelvey, eds. The SAGE Handbook of Complexity and Management. London, pp. 1-26.

Marti, M., 2007. Complexity Management: Optimizing Product Architecture of Industrial Products: Springer.

Meissner, S., 2009. Logistische Stabilität in der automobilen Variantenfließfertigung. Thesis (PhD). Technical University of Munich.

Meyer, C. M., 2007. Integration des Komplexitätsmanagements in den strategischen Führungsprozess der Logistik. Bern: Haupt.

Meyr, H., 2004. Supply chain planning in the German automotive industry. OR Spectrum vol. 26, pp. $447-$ 470.

Morieux, Y., 2011. Smart rules: Six ways to get people to solve problems without you. In: Harvard Business Review, pp. 78-86.

Moynihan, T., 2014. Apple's New Car System Turns Your Dashboard Into an iPhone Accessory[Online]. Wired. Available at: https://www.wired.com/2014/ 03/apple-carplay-system/ (Accessed 5 April 2017).

Muchna, C., Brandenburg, H., Fottner, J. and Gutermuth, J., 2018. Grundlagen der Logistik: Begriffe, Strukturen und Prozesse[Online]. Wiesbaden: Springer Gabler. Available at: http:// dx.doi.org/10.1007/978-3-658-18593-0.

Nikowitz, M., ed., 2016. Advanced Hybrid and Electric Vehicles: System Optimization and Vehicle Integration[Online]: Springer. Available at: http:// dx.doi.org/10.1007/978-3-319-26305-2.

Nutt, P. C. and Wilson, D. C., 2010. Crucial Trends and Issues in Strategic Decision Making. Handbook of Decision Making.

Paterson, M. S., ed., 1992. Boolean function complexity. Cambridge: Cambridge University Press.

Pawlikowski, K., Fruhner, D., Klingebiel, K., Toth, M. and Wagenitz, A., 2016. Benefits of an Integrated Hierarchical Data Structure for Automotive Demand and Capacity Management. The Eleventh International Multi-Conference on Computing in the Global Information Technology, pp. 20-25. Barcelona, Spain.

Pawlikowski, K., Toth, M., Fruhner, D. and Klingebiel, K., 2018. How electrified car concepts effect automotive logistics. Proceedings of the 25 th
International Annual EurOMA Conference, June 2426. Budapest, Hungary.

Pieper, M. and Ernst, C.-S., o.J. Technology, Value Added and Supply Chains of Electric Vehicles[Online]. Available at: http://enevate.eu/ 4c21c80c-c122-c50a-c386-693b23e00889 (Accessed 27 March 2018).

Pil, F. K. and Holweg, M., 2004. Linking Product Variety to Order-Fulfillment Strategies. Interfaces vol. 34, pp. 394-403.

Rosenberg, O., 2002. Kostensenkung durch Komplexitätsmanagement. In: Kostenmanagement. Wertsteigerung durch systematische Kostensteuerung., pp. 225-246.

Sargut, G. and McGrath, R., 2011. Learning to Live with Complexity. In: Harvard Business Review, pp. 68-76.

Scavarda, L. F., Reichhart, A., Hamacher, S. and Holweg, M., 2010. Managing product variety in emerging markets. International Journal of Operations \& Production Management vol. 30, pp. 205-224.

Schaffer, J., 2010. Entwicklung und Optimierung eines treiberbasierten Modells zur Bewertung varianteninduzierter Komplexitätskosten in industriellen Produktionsprozessen. Thesis (PhD). Leuphana University of Lüneburg.

Scholz-Reiter, B., Philipp, T., Beer, C. d., Windt, K. and Freitag, M., 2006. Einfluss der strukturellen Komplexität auf den Einsatz von selbststeuern-den logistischen Prozessen. In: Pfohl, H.-C., ed. Wissenschaft und Praxis im DialogSteuerung von Logistiksystemen - auf dem Weg zur Selbststeuerung ; [3. Wissenschaftssymposium Logistik in Dortmund. Hamburg: Dt. VerkehrsVerl., pp. 11-25.

Schuberthan, J. and Potrafke, S., 2007. Die Anforderungen des Kunden... In: Gehr, F. and Hellingrath, B., eds. Logistik in der Automobilindustrie: Innovatives Supply Chain Management für wettbewerbsfähige Zulieferstrukturen. Berlin Heidelberg: Springer, pp. 8-18.

Schuh, G., 2005. Produktkomplexität managen: Strategien - Methoden - Tools: Carl Hanser Fachbuchverlag.

Schuh, G. and Schwenk, U., 2001. Produktkomplexität managen: Strategien - Methoden - Tools. München, Wien: Hanser.

Stäblein, T., 2008. Integrierte Planung des Materialbedarfs bei kundenauftragsorientierter Fertigung von komplexen und variantenreichen Serienprodukten. Aachen: Shaker. 